\title{
Cross-border hospital use: analysis using data linkage across four Australian states
}

Access to

person-

level data

linked across

jurisdictions

... has

implications

for planning of

health service

delivery and

for longitudinal

follow-up

studies

Katrina Spilsbury PhD, GradDipPH, MBiostats

Diana Rosman BSc, GradDipComp, MMedSc

Janine Alan

$\mathrm{PhD}$

James H Boyd BSc(Hons)

Anna M Ferrante BA, DipEd, PhD

James B Semmen MSc, PhD, GAICD'

1 Curtin University Perth, WA

2 WA Department of Health, Perth, WA.

Katrina.Spilsbury@ curtin.edu.au

doi: 10.5694/mjal4.01414
$\mathrm{T}$ he benefits of using linked administrative data in healthrelated research were recognised by the Australian Government through the National Collaborative Research Infrastructure Strategy Roadmap in 2006. ${ }^{1}$ This roadmap outlined a multimillion dollar investment strategy in national capability for data linkage, which led to the establishment of the Population Health Research Network (PHRN) to coordinate and champion this initiative. ${ }^{2}$ The purpose of the PHRN was to establish data-linkage units in all Australian states, support the implementation of secure data delivery and the provision of remote-access laboratories for researchers, and to develop the Centre for Data Linkage (CDL) for national and cross-jurisdictional linkage.

The CDL was established within the Centre for Population Health Research at Curtin University in Western Australia. It provides the data linkage infrastructure necessary for cross-jurisdictional linkage of health-related data in Australia, and uses a best-practice data "separation principle". Under this principle, the process of data linkage is kept separate from the analysis of linked service data. Currently, projects requesting data linkage to Australian Government datasets, such as Medicare or Pharmaceutical Benefits Scheme data, must go through a risk-assessment process. If the risk to data security is found to be high, data linkage must be conducted through an Australian Governmentaccredited integrating authority.

Four "proof-of-concept" projects were selected to demonstrate the effectiveness of increased data linkage capacity in supporting nationally significant health research. ${ }^{3}$

Here, we present findings from the first of these projects that explored how cross-jurisdictional linkage can inform the nature and extent of cross-border hospital use and

\section{Abstract}

Objective: To determine the quality and effectiveness of national data linkage capacity by performing a proof-of-concept project investigating cross-border hospital use and hospital-related deaths.

Design, participants and setting: Analysis of person-level linked hospital separation and death registration data of all public and private hospital patients in New South Wales, Queensland and Western Australia and of public hospital patients in South Australia, totalling 7.7 million hospital patients from 1 July 2004 to 30 June 2009.

Main outcome measures: Counts and proportions of hospital stays and patient movement patterns.

Results: 223262 patients (3.0\%) travelled across a state border to attend hospitals, in particular, far northern and western NSW patients travelling to Queensland and SA hospitals, respectively. A further 48575 patients $(0.6 \%)$ moved their place of residence interstate between hospital visits, particularly to and from areas associated with major mining and tourism industries. Over 11000 cross-border hospital transfers were also identified. Of patients who travelled across a state border to hospital, 2800 (1.3\%) died in that hospital. An additional 496 deaths recorded in one jurisdiction occurred within 30 days of hospital separation from another jurisdiction.

Conclusions: Access to person-level data linked across jurisdictions identified geographical hot spots of cross-border hospital use and hospitalrelated deaths in Australia. This has implications for planning of health service delivery and for longitudinal follow-up studies, particularly those involving mobile populations.

hospital-related deaths. A secondary aim was to evaluate the impact that cross-jurisdictional linkage had on estimating hospital standardised mortality ratios; these findings will be published separately.

Typically, single-jurisdiction studies investigating hospital use and hospital-related deaths have been unable to account for patients crossing state borders. This is problematic for densely populated border regions like northern New South Wales, for example, where patients are likely to attend specialist hospitals in Queensland.

This is the first Australian study to combine hospital and death data from multiple jurisdictions at the person level. A national data-linkage approach was used to bring together all of the hospital and death records of individuals, even when they crossed state borders. Linked hospital discharge and death registration data from NSW, WA, South Australia and Queensland were used in this study.

\section{Methods}

This was a retrospective cohort study of all people who separated from a hospital in NSW, WA, SA or Queensland from 1 July 2004 to 30 June 2009. Hospital separation records and death records were available for both public and private hospitals in NSW, WA and Queensland, but only public hospital records were available from SA.

Ethics approval was granted by human research ethics committees of the WA Department of Health, Curtin University, SA Department of Health and Ageing, NSW Population and Health Services, and Queensland Health. The extensive negotiation and approvals process required to conduct this study commenced in 2009. At that time, data from Victoria, the territories and Tasmania were unavailable for linkage. Datasets from NSW, Queensland, WA and SA containing the CDL-generated national linkage key were delivered to the analyst in late 2013. 


\section{Data sources}

NSW: The NSW Health Department Admitted Patient Data Collection included inpatient records from all NSW private, public, psychiatric and repatriation hospitals and multipurpose services and day-procedure centres. NSW data were provided through the Centre for Health Record Linkage.

$S A$ : Hospital separation data were provided through SA-NT DataLink. Data on SA public hospital inpatient separations from the Integrated South Australian Activity Collection included all SA inpatient records from public acute and psychiatric hospitals. Data from SA private hospitals were unavailable at the time of the study.

WA: The WA Hospital Morbidity Data System collects inpatient data from public and private acute and psychiatric hospitals and private daysurgeries. ${ }^{4}$ All data were obtained from the WA Department of Health.

Queensland: The Queensland Hospital Admitted Patient Data Collection includes all admitted patient separations from public hospitals, public psychiatric hospitals, licensed private hospitals and daysurgery units.

Death records were obtained from the four jurisdictional Registries of

1 Number of acute care hospital stays per 10000 hospital stays recorded for travellers by their state of residence and the jurisdiction of the receiving hospital and, for movers, by the state of residence before moving and the jurisdiction of the hospital stay after moving, 1 July 2004 to 30 June 2009

\begin{tabular}{|c|c|c|c|c|c|c|c|c|}
\hline \multirow{2}{*}{$\begin{array}{l}\text { Original place } \\
\text { of residence }\end{array}$} & \multicolumn{4}{|c|}{ Hospital stays by travellers } & \multicolumn{4}{|c|}{ Post-move hospital stays by movers } \\
\hline & NSW & WA & QLD & SA & NSW & WA & QLD & SA \\
\hline NSW & - & 11.1 & 221.6 & 41.9 & - & 13.3 & 33.0 & 12.8 \\
\hline WA & 4.1 & - & 4.3 & 8.8 & 3.3 & - & 6.7 & 8.2 \\
\hline QLD & 75.1 & 9.3 & - & 11.2 & 14.7 & 11.2 & - & 10.6 \\
\hline SA & 4.4 & 4.3 & 5.0 & - & 1.8 & 4.2 & 3.2 & - \\
\hline VIC* & 68.7 & 9.7 & 20.5 & 67.2 & 1.1 & 0.8 & 1.0 & 2.0 \\
\hline TAS* & 2.6 & 1.5 & 3.1 & 2.6 & 0.1 & 0.1 & 0.2 & 0.1 \\
\hline NT* & 2.2 & 5.7 & 6.5 & 60.4 & 0.2 & 0.8 & 0.5 & 1.8 \\
\hline ACT* & 23.9 & 0.7 & 1.9 & 1.6 & 0.8 & 0.1 & 0.2 & 0.1 \\
\hline Total & 180.9 & 42.3 & 262.9 & 193.8 & 22.0 & 30.5 & 44.9 & 35.7 \\
\hline
\end{tabular}

$\mathrm{NSW}=$ New South Wales. WA = Western Australia. $\mathrm{QLD}=$ Queensland. SA = South Australia. VIC = Victoria. TAS = Tasmania. NT $=$ Northern Territory. $A C T=$ Australian Capital Territory.

* Data pertaining to patients resident in the four non-participating jurisdictions were complete for travellers if they were admitted to a hospital in any of the four participating jurisdictions. The estimated number of hospital stays for movers from non-participating jurisdictions is an underestimation, as most hospital stays before they moved would likely have been based in the non-participating jurisdiction for which no data were available.

Births, Deaths and Marriages according to state-based data-access mechanisms. The linkage of over 44 million records was undertaken by the CDL; details are described elsewhere (manuscript submitted).

\section{Data cleaning}

After linkage, de-identified data were supplied to the research team. The data underwent extensive cleaning and manipulation. Variable names and variable coding were standardised across the datasets by using the lowest common denominator. For example, NSW hospital separations data included a hospital peer group variable with 23 categories whereas SA supplied eight categories, so NSW categories were collapsed to match the SA categories.

2 Number of acute care stays in hospitals in New South Wales, Western Australia, Queensland or South Australia by the statistical local area (SLA) of residence of travellers (A)* and movers (B) ${ }^{\dagger}$

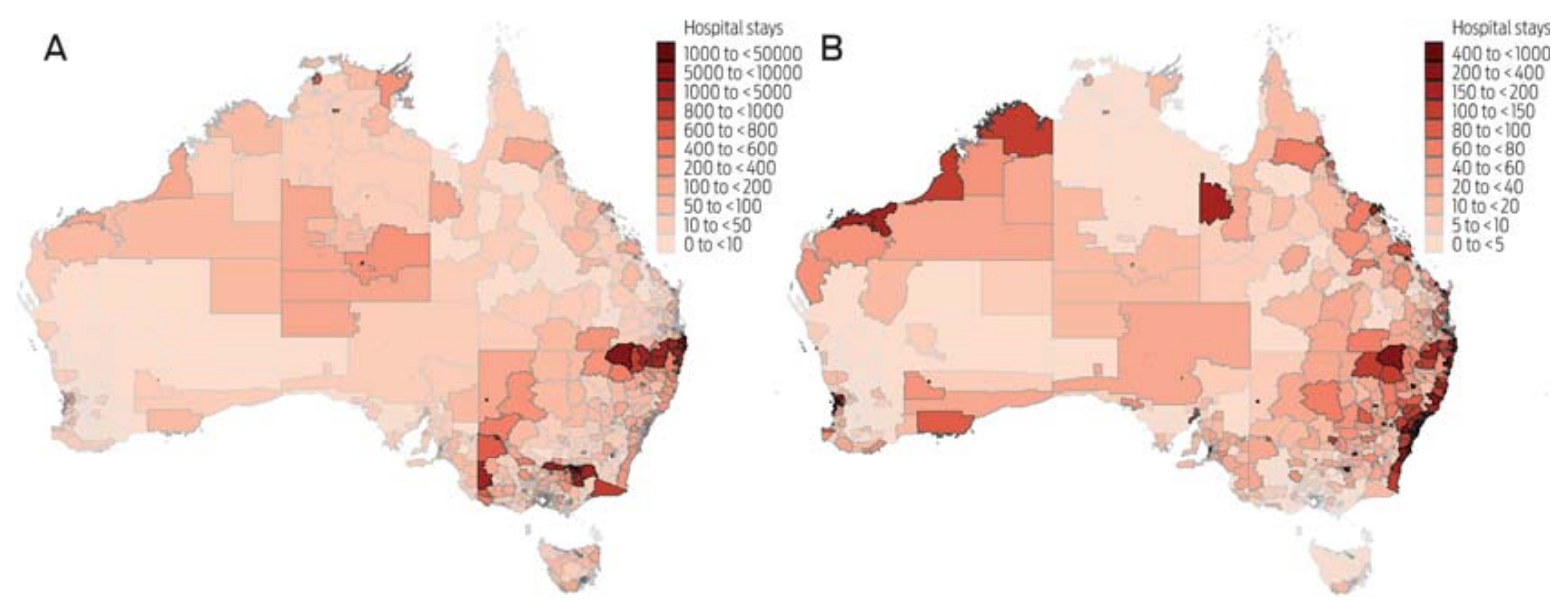

*Density of shading is attributed to the SLA of residence of the traveller. †Density of shading of post-move hospital stays is attributed to the SLA of the pre-move residence.

Note that the number of movers is not directly comparable with the number of travellers because movers had to have had at least two hospital stays in 5 years, whereas travellers could have had only one hospital stay. SLAs of states that did not provide data for this study are shaded because residents living in these SLAs travelled to a hospital within the four participating states. Hospital stays for movers from non-participating jurisdictions will be underestimated as most pre-move hospital stays would have been based in the non-participating jurisdiction. 
3 Number of hospital stays involving cross-border hospital transfers and cross-border registered deaths within 30 days of separation from the last hospital stay, 1 July 2004 to 30 June 2009

\begin{tabular}{|c|c|c|c|c|c|c|c|c|c|c|}
\hline \multirow{2}{*}{$\begin{array}{l}\text { Jurisdiction } \\
\text { of sending/ } \\
\text { last hospital } \\
\text { stay }\end{array}$} & \multicolumn{5}{|c|}{$\begin{array}{l}\text { Cross-border hospital transfers } \\
\text { (jurisdiction of receiving hospital) }\end{array}$} & \multicolumn{5}{|c|}{$\begin{array}{l}\text { Cross-border 30-day deaths } \\
\text { (jurisdiction of death registration) }\end{array}$} \\
\hline & NSW & WA & QLD & SA & Total & NSW & WA & QLD & SA & Total \\
\hline NSW & - & 12 & 8114 & 1316 & 9442 & - & 7 & 196 & 25 & 228 \\
\hline WA & 27 & - & 26 & 12 & 65 & $<5$ & - & $<5$ & $<5$ & 9 \\
\hline QLD & 1258 & 8 & - & 12 & 1278 & 219 & $<5$ & - & 12 & 234 \\
\hline SA & 299 & 8 & 24 & - & 331 & $<20$ & $<5$ & $<5$ & - & 25 \\
\hline Total & 1584 & 28 & 8164 & 1340 & 11116 & 239 & 12 & 205 & 40 & 496 \\
\hline
\end{tabular}

NSW = New South Wales. WA = Western Australia. QLD = Queensland. SA = South Australia.

\section{Source of cross-border hospital transfers recorded over 5 years between New South Wales (enlarged), Western Australia, Queensland and South Australia*}

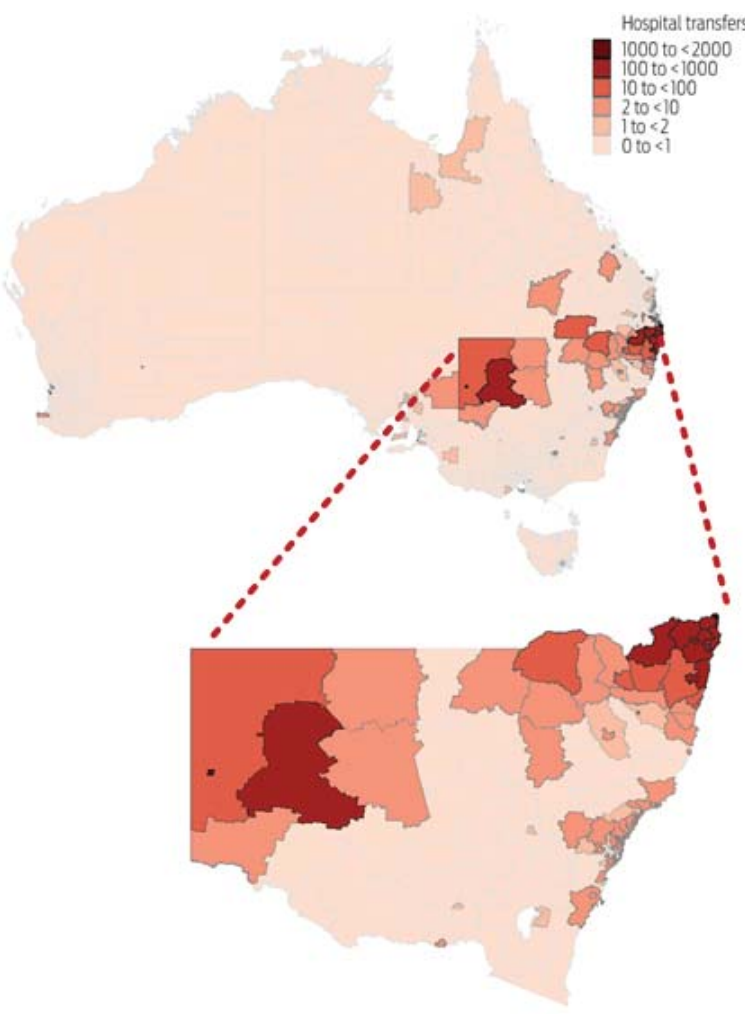

* Density of shading is attributed to the statistical local area (SLA) of residence of transferred patients.
Episodes of care that were missing vital data such as age, sex, principal diagnosis or mode of separation were excluded, as were separations indicating that the health care facility was not a hospital or that a procedure had been cancelled. These types of jurisdictional differences were identified through systematic cross-checking and with reference to published metadata and local expertise. In some cases it was impossible to reduce this heterogeneity. In NSW, for example, deaths in hospital emergency departments were included as in-hospital deaths whereas this was not the case for the other three jurisdictions. There was no way to identify NSW deaths in emergency departments within the datasets used for this study. Overall, 1.44 million records were excluded during the standardisation process. Further details about the data cleaning and standardisation are available on request.

\section{Variable definitions}

Hospital transfer was defined as an episode of care with a separation mode value that indicated either transfer to another acute hospital or a statistical discharge within the same hospital. Up to 48 hours was allowed for a patient to transfer from one hospital to another. Transfer sets (sequences of transfer episodes of care that made up the completed hospital stay for an individual) where the first episode of care was not an acute care admission were excluded. Transfer sets involving a transfer from a hospital in one jurisdiction to a hospital in another jurisdiction were referred to as cross-border hospital transfers.
Hospital stays of interest were defined as having had:

- an acute care type for single episodes of care and for the first episode of care of a hospital transfer set;

- a hospital stay separation date in the period 1 July 2004 to 30 June 2009;

- a total length of stay of less than 365.25 days;

- an Australian postcode of residence (excluding island territories) for the patient involved;

- complete demographic information for the patient involved; and

- a principal diagnosis or principal procedure code and mode of separation recorded.

This definition of hospital stays was designed to match that typically used when estimating hospital standardised mortality ratios, a secondary aim of this project.

Hospital-related deaths were defined as deaths occurring between the day of hospital admission and 30 days after separation from hospital. If the jurisdiction where the death was registered was different from the jurisdiction of the last hospital stay, the death was considered a cross-border 30-day death.

\section{Defining patient cross-border hospital flows}

Travellers were defined as patients who crossed a jurisdictional border to attend the hospital. For example, a patient separating from a NSW hospital with a residential postcode of 6102 would be classified as a WA to NSW traveller.

Movers were defined as patients who had: (i) had at least two hospital stays in more than one jurisdiction with the postcode of residence matching the jurisdiction of the hospital (eg, a patient who had a NSW hospital stay recorded with a 2234 postcode of residence in 2004 followed by a WA hospital stay record with a 6102 postcode of residence in 2007); or (ii) had a previous hospital stay as a traveller in any jurisdiction followed by a hospital stay in the jurisdiction of residence, provided that the 
residential jurisdiction was not the same as the previous hospital stay as a traveller (eg, a patient who lived in the Northern Territory and travelled to Adelaide for a hospital stay whose next hospital stay was also in SA, but whose residential postcode indicated the patient had since moved to SA).

\section{Mapping of cross-border patient flows}

Spatial data were used to create choropleth maps to visually demonstrate cross-border patient flows. ${ }^{5}$ Residential postcodes of patients who had had hospital stays were assigned to a 2006 Statistical Local Area (SLA) and a weighting was applied such that the number of hospital stays within a postal area was multiplied by the relative proportion of the postcode that fell within an SLA boundary. All data manipulation and mapping was performed with Stata 13 (StataCorp).

\section{Results}

There were almost 19 million acute care hospital stays involving 7.7 million patients in NSW, WA, Queensland and SA hospitals over the 5 years from 1 July 2004 to 30 June 2009 that were brought together using a national linkage key. NSW and Queensland had the largest number of hospital stays and patients. There were relatively fewer hospital stays in SA because private hospital data were unavailable. NSW recorded the highest proportion $(4.9 \%)$ and WA the lowest proportion $(3.6 \%)$ of hospital transfers over the 5-year study period. The median number of hospital stays per patient over 5 years was one (interquartile range, $1-3$ stays).

\section{Travellers}

There were 223262 individuals (3.0\%) who had 352969 acute care hospital stays $(1.9 \%)$ recorded as a traveller, although the proportion varied geographically. Of the four jurisdictions, NSW was the source of the largest number of hospital stays by travelling residents (140246), with $93.5 \%$ (131 149) travelling to Queensland hospitals. Queensland and SA received the highest proportions of travelling patients (Box 1). Patients living in Victoria accounted for relatively high proportions of hospital stays in SA, Queensland and NSW.

WA received the lowest number of travelling patients. Geographical regions where travellers to NSW, Queensland, SA or WA hospitals lived were clustered in northern and western NSW, northern and western Victoria, central Australia, Arnhem Land in the NT and the major capital cities (Box 2A).

\section{Movers}

There were 48575 individuals $(0.6 \%)$ with hospital stays recorded as residents in two or more jurisdictions over the 5-year study period. This group moved 59387 times over the 5 years. Queensland hospitals had the highest proportions of hospital stays by movers over the 5 -year study period $(0.45 \%)$, with most coming from NSW. Hospitals in NSW had the lowest proportion of hospital stays by movers, less than half that of Queensland hospitals ( $0.22 \%)$.

The geographical distribution of movers differed to those of travellers (Box 2B). Patients who moved tended to live in regions typically associated with the mining industry, such as Mt Isa and the Bowen Basin in Queensland and the Pilbara, Gascoyne, Kimberley and Kalgoorlie regions of WA. Movers were also more prevalent from important tourist regions, such as the Coral Coast in WA, Tropical North Queensland, and the Whitsunday Islands and Capricorn Coast in Queensland. When population density was taken into account, rural and remote areas tended towards having higher proportions of movers compared with major metropolitan areas (map not shown).

\section{Cross-border hospital transfers}

Over 11000 acute care hospital transfers across state borders of the four jurisdictions were identified (Box 3). NSW was the source of origin for most hospital transfers among these four jurisdictions (Box 4) and Queensland and SA received most of the NSW patients being transferred. WA received fewest cross-jurisdictional hospital transfers.

\section{Cross-border hospital-related deaths}

There were 206721 in-hospital deaths observed in the 5-year study period and, of these, 2824 (1.4\%) were in-hospital deaths of travellers who died in a jurisdiction different from that of their normal residence. Of the 66324 deaths that occurred within 30 days of separating from hospital, $496(0.7 \%)$ occurred in a different jurisdiction to that of the last separating hospital (Box 3).

\section{Discussion}

Cross-jurisdictional person-level linkage of hospital records and death registrations identified patterns of hospital use in Australia that have not been measured previously. From 1 July 2004 to 30 June 2009, 3\% of all hospital patients had travelled across a state border before an acute care hospital stay. These finding have important implications for both health services planning and the ability to evaluate patient health outcomes in these border regions accurately. Longitudinal health studies that rely on administrative data from a single jurisdiction for hospital morbidity and mortality (in-hospital and within 30 days of leaving hospital) outcomes are at risk of follow-up biases for participants living in border regions, particularly in northern and western NSW, Victoria and the NT.

In this study, we followed hospital users who moved their place of residence between jurisdictions over the study period. Based on the residential location before the move, movers included a subpopulation of workers or residents of mining and tourism areas of Australia. This suggests that cross-jurisdictional linkage could be of great benefit to studies looking at occupational exposures and health outcomes that require long followup periods.

Only four jurisdictions were included in our study, but there was evidence that many Victorian patients travel to hospitals in other jurisdictions, particularly those living close to SA and NSW borders. Residents of the NT were also mobile when attending hospitals. A complete national 
approach to cross-jurisdictional linkage would markedly increase the ability to answer questions about the whole of Australia, and gain indepth knowledge of the variation between all jurisdictions.

Currently cross-jurisdictional data are received in a variety of formats and coding schemes that required extensive cleaning and standardising. Some records and variables were not supplied by some jurisdictions at all (eg, private hospital data in SA). This heterogeneity in data arises for various reasons, including differences in jurisdictional legislation, operating environments and the coding practices of state-based custodians.

Future research would benefit from the development of national metadata and standard definitions that would enable data across jurisdictions to be more readily integrated and understood. A major advantage would be greater confidence by data custodians that their data were being used and interpreted correctly by researchers. In our study, for example, a direct comparison of hospital mortality rates across jurisdictions would be misleading without considering that deaths in emergency departments were included in NSW hospital data, but not in those of the other jurisdictions.

A more centralised approach to standardising data definitions would also provide long-term efficiency gains. While considerable resources and cooperation would be needed to establish such a standard, the time and savings in project-based research funding would be significant in the long term.

Access to person-level administrative data that have been linked across jurisdictions adds complexity and heterogeneity to the research process. The advantages include more complete follow-up, increased ability to study rare outcomes or disease, and to study geographically active populations. For policymakers, governments and health care providers, cross-jurisdictional linked data could provide a more accurate and cost-effective use of existing data collections for evaluating patient outcomes and health care service use, particularly where these are located near borders.

Acknowledgements: The Population Health Research Network (PHRN) is an initiative of the Australian Government being conducted as part of the National Collaborative Research Infrastructure Strategy. This study would not have been possible without the collaboration, assistance and expertise provided by a large number of people, including Lee Taylor, Kim Lim, Baohui Yang and Zoran Bolevich from the NSW Ministry of Health; Almond Sparrow and Stacy Vasquez from SANT DataLink; Paul Basso, Tina Hardin and Tomi Adejoro from the South Australian Department for Health and Ageing; Helen Paues from the Registry of Births, Deaths and Marriages in SA; Darren Shaw at Promadis; Jessica Lee, Alexandra Godfrey and Paul Stevens from the WA Department of Health; the Registry of Births, Deaths and Marriages in WA; the Health Statistics Branch, Queensland Department of Health; Julie Hall and Erica Finlay at Queensland Registry of Births, Deaths and Marriages; Sean Randall and Jacqui Bauer at the Centre for Data Linkage; Merran Smith, Felicity Flack, Angela Rate, Natalie Wray, Emma Fuller and Tony Woollacott at the PHRN Program Office; James E Harrison, Flinders University; Bruce Armstrong, University of Sydney; and Neville Board, Australian Commission on Safety and Quality in Health Care.

Competing interests: Katrina Spilsbury received financial support from the PHRN.

Received 3 Oct 2014, accepted 12 Feb 2015.

References are available online at www.mja.com.au.
1 National Collaborative Research Infrastructure Strategy Strategic Roadmap. Canberra: Australian Government Department of Education, 2006. http://docs.education.gov.au/ system/files/doc/other/national_ collaborative_research_infrastructure_ strategic_roadmap_2006.pdf (accessed Jan 2015).

2 Boyd JH, Ferrante AM, O'Keefe CM, et al. Data linkage infrastructure for cross-jurisdictional health-related research in Australia. BMC Health Serv Res 2012; 12: 480.

3 Rosman D, Spilsbury K, Alan J, et al. Multi-jurisdictional linkage in Australia: proving a concept Aust N Z J Public Health 2015. In press.

4 Hospital Morbidity Data System. HMDS reference manual. Perth: Government of Western Australia Department of Health, 2014 http://www.health. wa.gov.au/healthdata/docs/Hospital_ Morbidity_Data_System_Reference_ Manual.pdf (accessed Jan 2015).

5 Pisati M. Simple thematic mapping. Stata J 2004; 4: 361-378. 